\title{
SMALL HARBOURS RISKS: LOWERING FOR FISHERY AND INCREASING EROSION. THE CASE OF PORTINHO DA AGUDA (NW PORTUGAL)
}

\author{
Helena Granja, Department of Earth Sciences, University of Minho, Portugal, hgranja@dct.uminho.pt \\ Luisa Bastos, University of Porto, Icbastos@fc.up.pt \\ José Pinho, Department of Civil Engineering, University of Minho, Portugal, jpinho@civil.uminho.pt \\ José Gonçalves, University of Porto, jgoncalves@fc.up.pt \\ Renato Henriques, Department of Earth Sciences, University of Minho, Portugal, \\ rhenriques@dct.uminho.pt \\ Ana Bio, CIMAR/CIIMAR - Centro Interdisciplinar de Investigação Marinha e Ambiental, Universidade \\ do Porto, Rua dos Bragas, 289, 4050-123 Porto, Portugal, anabio@ciimar.up.pt \\ Américo Magalhães, Astronomical Observatory, Faculty of Science, University of Porto, Portugal, \\ americo.magalhaes@fc.up.pt
}

\begin{abstract}
The harbour Portinho da Aguda was established between October 2001 and July 2002, at Aguda village. The area presented some rocky outcrops that, in some way, protected the coastal border against direct wave impact, on a coastal stretch where erosion has been a continuing problem. In an attempt to create a protected area for the entrance and way out of the community's small fishing boats a detached curved breakwater was built.

After some months, still during the works, a wedge beach was created against the temporary groin, promoting the enlargement of the beach located updrift and the erosion of the downdrift coastal segment (Granja Beach). To remediate this situation, sand transfer from the updrift area was done, to compensate the accentuated loss of sediments of Granja Beach, a famous old seaside resort. But, due to the very high energetic conditions, sands did not remain on the beach, and new spring to early summer recharges became necessary.

Based on results from a comprehensive monitoring program of the coastal border north and south of Aguda between 2001 and 2009 with DGPS, sedimentary budgets were calculated and morphological changes identified, comparing situations before and after breakwater construction. Breakwater impacts on neighbouring areas of the harbour are presented, as are the evolution trends of the harbour itself. Some possible mitigation measures are pointed out and the efficiency and relevance of this kind of coastal structures is discussed.
\end{abstract}

Keywords: breakwater impact, coastal erosion, morphodynamics.

\section{Introduction}

The Northwestern coastal zone of Portugal is mesotidal with a highly energetic wave climate. Main wave crest orientation is from NW, inducing a drift current from North to South. However, this current is in some areas inverted due to the presence of some obstacles that promote wave diffraction. This is the case of the Leixões harbour breakwaters (Fig. 1) that promote a South-North drift enlarging Matosinhos beach to the North. The Douro estuary spit points to North by a South-North drift due to wave diffraction around the ebb-tidal delta and 
some outcrops (beach accretion against the North jetty of the Douro estuary). South of it, the main drift is again North-South, promoting the accumulation of sediments updrift transverse obstacles (e.g. Espinho groins and Madalena submerged outfall) and increasing erosion downdrift.

Aguda is located on the coastal stretch South of the Douro estuary, where the coastal border is narrow, with a subtidal rocky platform and many outcrops creating small tombolos between pocket beaches.

The high-energy wave climate and storm events represent a challenge for engineering when a coastal stretch needs some kind of intervention. Fishery communities, though presently very small, fight against adverse wave conditions when they want to go out or return with their boats. During the last years, in response to the demands of those communities, small fishery harbours, using detached breakwaters, were built, like at Pedra Alta and Aguda.

In this study, results of a comprehensive coastal monitoring program at the Aguda breakwater surrounding beaches, involving different methodologies, are presented and the obtained results are discussed.

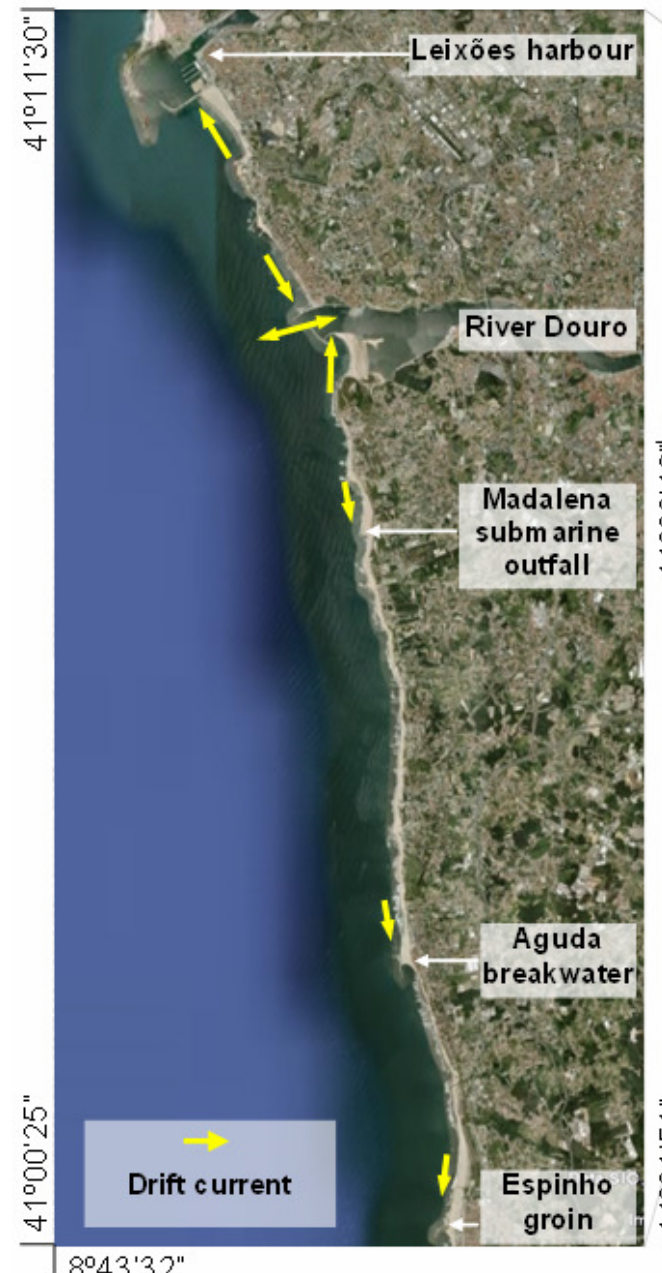

$8^{\circ} 43^{\prime} 32^{\prime \prime}$
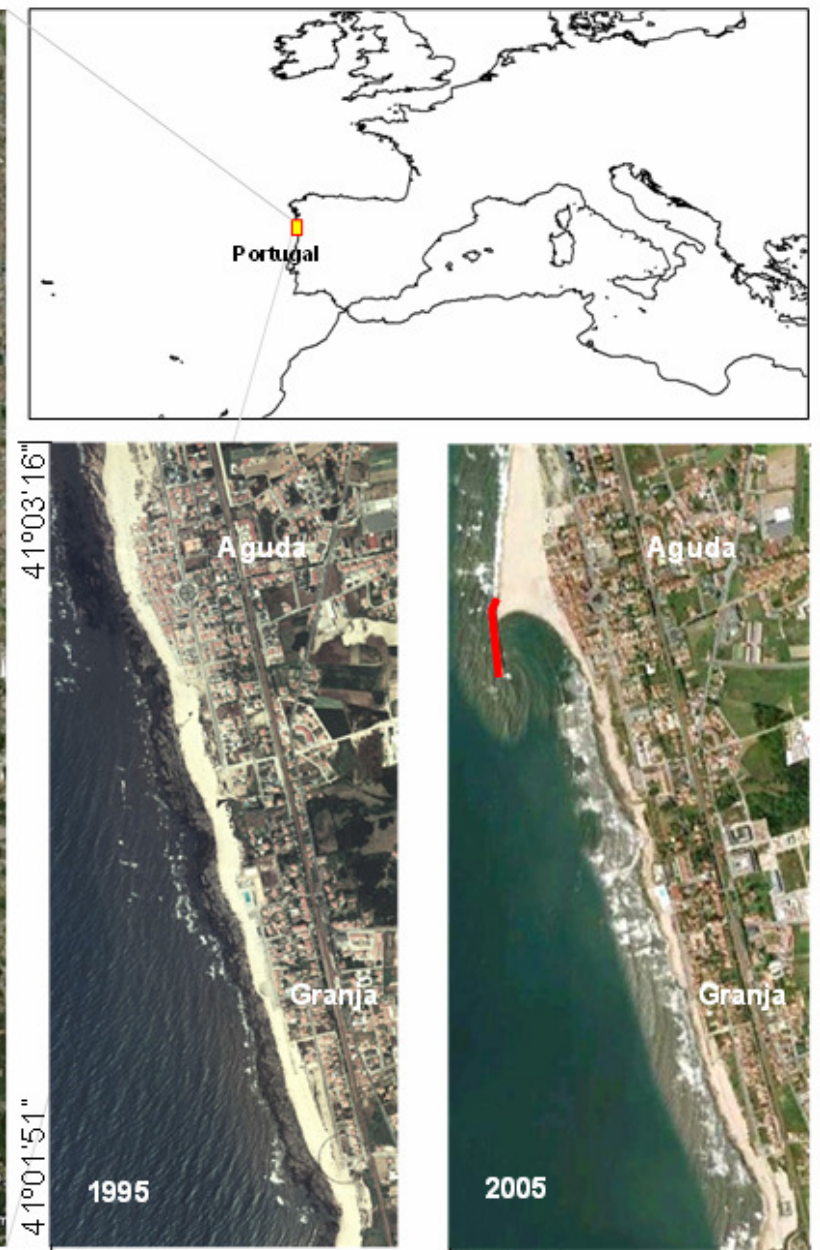

$8^{\circ} 39^{\prime} 28^{\prime \prime}$

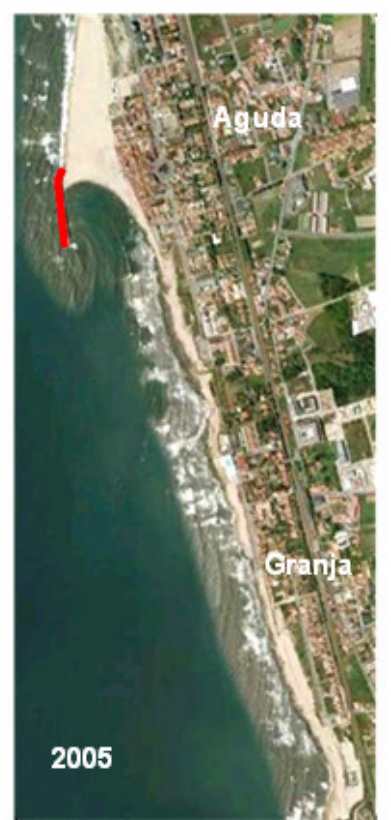

$8^{\circ} 38^{\prime} 41^{\prime \prime}$

Fig. 1. Location of the Aguda and Granja beaches in northern Portugal, and aerial images of the coastal stretch before (1995) and after breakwater construction (2005). Images represent about $1 \mathrm{~km} \times 2.6 \mathrm{~km}$ ground surface. The detached breakwater is drawn in red. 


\section{Portinho da Aguda coastal stretch}

The Portinho da Aguda was built between October 2001 and July 2002, at Aguda village. This coastal stretch presents a rocky platform (Fig. 1 - 1995 aerial image) that protected the coastal border against the direct wave impact, on an area where the erosion impact knowledge is old.

The harbour was created building a detached curved breakwater, anchored in rocky outcrops. A temporary groin, starting on the beach, was made to allow the access and transport of material for the breakwater construction (Fig. 2).

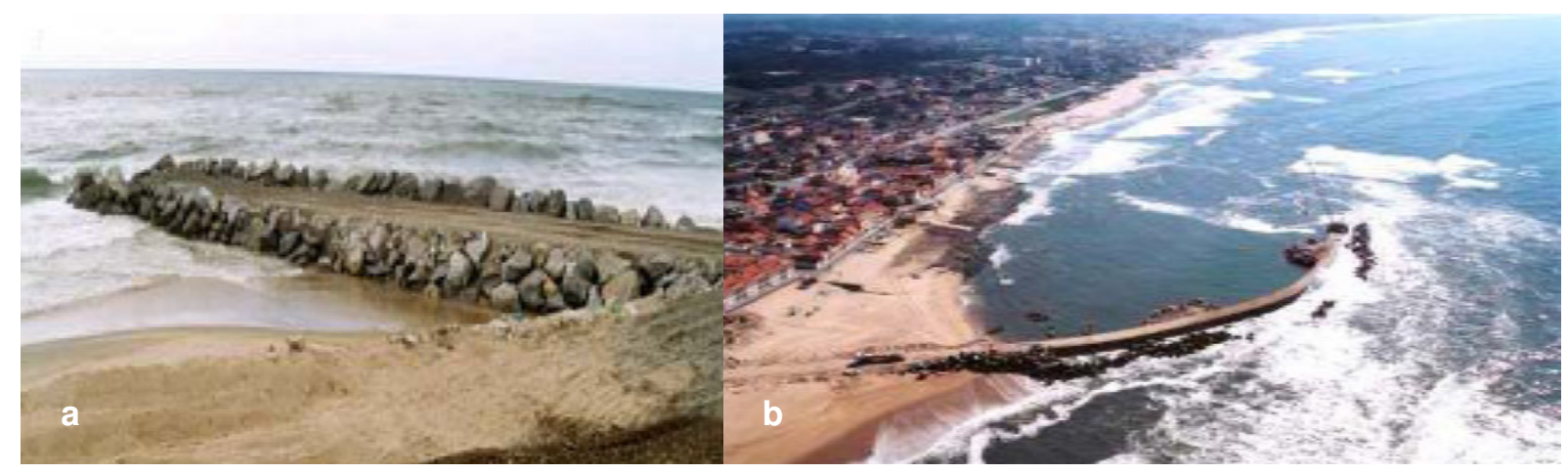

Fig. 2. Construction of the Aguda breakwater: a) access groin; b) final works (adapted from INAG, 2010)

After some months and still during the works of the breakwater, a wedge beach formed against the temporary groin, promoting the enlargement of the beach located updrift and the erosion of the downdrift coastal segment (Granja Beach).

After the works conclusion, the temporary groin was not removed (Rosa-Santos et al., 2009). This fact did not allow the reestablishement of the littoral drift, promoting sand retention against the groin and sedimentary deficit on the downdrift segment.

To remediate this situation, sand transfer from the updrift area to Granja Beach was done, in an attempt to compensate the accentuated loss of sediments at that famous old seaside resort. But, due to the very high energetic conditions, sands do not stay very long on the beach, making recurrent spring or summer recharges necessary to maintain at least minimal conditions for beach users.

\section{Methods}

\subsection{Comprehensive monitoring program}

Monitoring of the Aguda beach started in 2001. Later on, monitoring was expanded towards Granja beach to cover the beach erosion observed after the breakwater construction. We used 10 surveys collected in winter to early spring, to avoid direct effects from the yearly artificial beach nourishment. The March 2001, 2002, 2003 and 2004, February 2005, March 2006, December 2007 and March 2008 surveys were based on DGPS (Differential Global Positioning System) kinematic surveys; the April 2009 and March 2010 surveys were airborne, based on georeferenced digital photography. Whenever possible, campaigns were performed during low tide of spring tide conditions, to allow comparison of shape, area and volume between campaigns. 
Land-based measurements were taken contouring the low-tide water line and the dunes, and on a grid of longitudinal and horizontal profiles. Although always based on kinematic DGPS, different survey methodologies were used. First campaigns (2001-2003) were done with onfoot equipment (Fig. 3, a), which was later replaced by a two antenna DGPS system mounted on a motor-quad (Fig. 3, b) and finally (in 2009) by a videogrammetric mobile mapping system (MMS) (Fig. 3, c). Details about the methodologies used can be found in Baptista et al. (2008a,b) and Madeira (2007). The 3D positioning precision of the kinematic DGPS processing technique is better than $5 \mathrm{~cm}$. Concerning the MMS system, special care has to be given to the determination of the inclination of the cameras baseline as the final accuracy of the coordinates is very sensitive to the error in roll (Bastos et al., 2009). DTM models with heights above chart datum (the mean sea level is $2 \mathrm{~m}$ below CD) on a regular $1 \times 1 \mathrm{~m}$ grid were computed through Triangulation with Linear Interpolation (TLN) using Surfer 8 software.
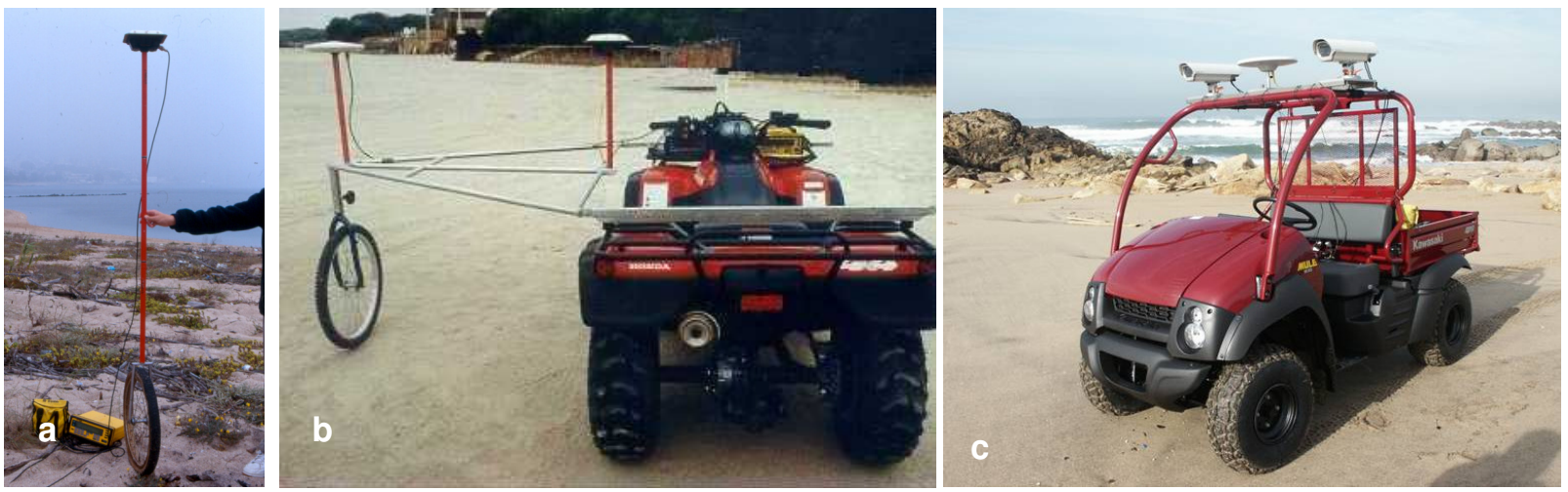

Fig. 3. Mobile mapping gear: a) single-antenna equipment; b) vehicle equipped with two antennas on an articulate arm, c) four-wheel vehicle with two antennas and videogrammetric equipment.

Aerial images were acquired with a digital Zeiss-Intergraph DMC camera, allowing a ground sampling distance (GSD) of 0.1 meters during the flights, which took a few minutes only. The observed $2.7 \mathrm{~km}$ stretch was covered by a total of 20 photos in two strips, with $60 \%$ forward overlap and $30 \%$ side overlap which took a few minutes only. The observed $2.7 \mathrm{~km}$ stretch was covered by a total of 20 photos in two strips, with $60 \%$ forward overlap and $30 \%$ side overlap. Digital Terrain Models (DTM) were obtained from the stereoscopic information provided by the pan-chromatic images, with $7680 \times 13824$ pixels and a pixel size of $12 \mu \mathrm{m}$. Images were acquired by a private company, using GPS/INS direct georeferencing equipment (IGI Aerocontrol) and standard processing techniques. The fact that no GCP collection was required for an aerial triangulation is an important advantage. It allows for a very fast response in deriving DTM and orthoimages after the data acquisition, and it allows for reasonably accurate mapping at locations were only natural features exist, such as in beaches, dunes and river estuaries.

GPS relative positioning of the airplane was obtained using the Portuguese network of GPS permanent stations (IGP, 2009), and coordinates were computed in the ETRS89 reference system. Planimetric and altimetric accuracy of the DTM points were of the order of $0.3 \mathrm{~m}$ (Gonçalves et al., 2010). DTM were obtained using the DPCOR program, of the BLUH software packages (Jacobsen, 2000, Rieke-Zapp and Nearing, 2005). 


\subsection{GIS analysis}

DTM were analysed and mapped in a GIS (using ArcView 9.3 and its Spatial Analyst and 3D Analyst modules), calculating beach area and volume and their changes over time, and identifying areas of erosion or accretion between surveys. To distinguish the dynamics around the breakwater from the downdrift beach dynamics, we considered the northern part of the surveys separately, and, because early surveys were restricted to the Aguda beach area, we considered the Granja beach as a separate stretch too. Sediment budget analysis is therefore done for the northern, centre and southern stretch separately.

While land-based surveys were restricted by accessibility, digital aerial photography covered a vaster area, including inland dunes and intertidal rocky outcrops. We masked the survey inland limits according to the land-based surveys, but did not distinguish the rocks from the waterline. Airborne and land-based surveys are therefore not directly comparable in terms of area and volume. Land-based survey results were further validated, comparing observed and DTM estimated heights and calculating their absolute differences.

\subsection{Wave climate}

Coastal morphodynamics in this coastal stretch is mainly shaped by wave climate dynamics. Available wave data for the Leixões harbour was analyzed for the period between May 2001 and September 2009. Moreover, a numerical model based on a time-domain solution of Boussinesq-type equations (Nawogu and Demirbilek, 2001), was implemented to analyze local wave propagation. This model can simulate most of the hydrodynamic phenomena of interest in coastal regions including (i) shoaling, (ii) refraction, (iii) diffraction, (iv) full/partial reflection and transmission, (v) bottom friction, (vi) nonlinear wave-wave interactions, (vii) wave breaking and runup, (viii) wave-induced currents, and (ix) wave-current interaction.

\section{Results and discussion}

The spatial delimitation of erosion (hot colors) and accretion (cold colors) areas in the surrounding of the breakwater is depicted in Fig. 4. Sediments retention starts during the construction phase against the temporary groin that was not removed after works conclusion. It occurs either against the groin/breakwater and inside the protected area. The annual net sediment balance (Fig. 5) presents an evident accumulation tendency at North stretch (average $50 \times 10^{3} \mathrm{~m}^{3}$ per year). At the central stretch it is evident an alternate behaviour (erosion alternating with accretion periods) resulting from the sand transfer from the updrift area. This sediment transfer was not enough to compensate the South segment sediment deficit. At this segment the maximum annual sediment deficit was about $20 \times 10^{3} \mathrm{~m}^{3}$ with an average of $1,3 \times 10^{3} \mathrm{~m}^{3}$ (this result includes the sediment transfer volumes). Erosion inside the protected area can result from sand transfer works or transport by wave induced currents (wave diffraction near the breakwater or waves from SW direction (Fig. 6).

The breakwater construction had a significant impact in the local wave dynamics as can be seen in Fig.6. The most frequent wave directions are from W $(60 \%$ of the buoy records in the period of May 2001 to September 2009) followed by NW (34\% of the buoy records) and SW ( $5 \%$ of the buoy records). For the most frequent wave directions, diffraction tends to interrupt the previously installed North-South coastal drift tendency in this coastal segment. During storms from S and SW this coastal defense structure is inefficient and can be significantly affected by sediment depositions inside the artificial bay, forcing the execution of dredging works. 

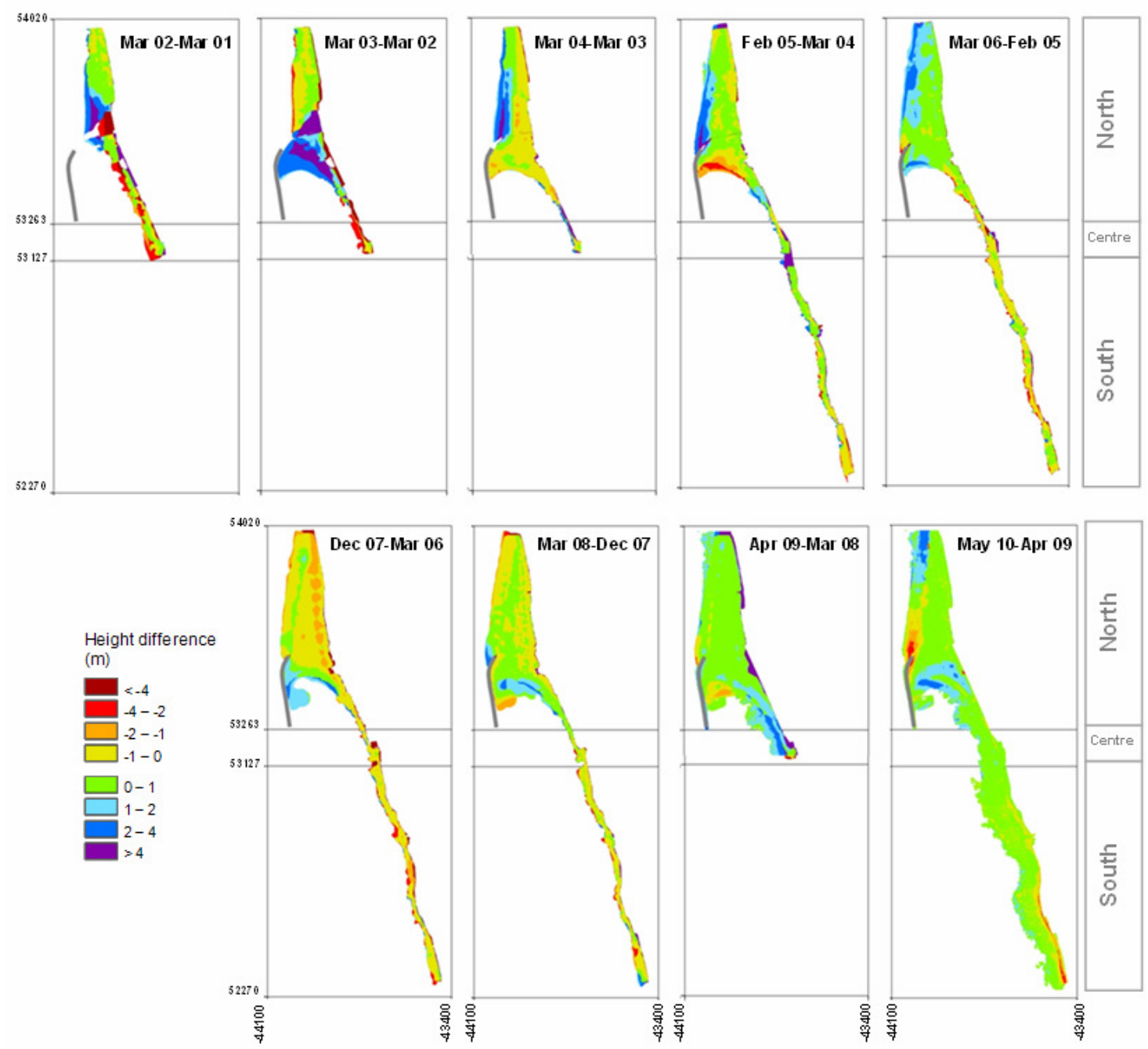

Fig. 4. Areas of erosion and accretion between surveys (breakwater: grey line). Surveys were landbased until March 2008 and air-borne thereafter. Lines separate the northern (Aguda), central and southern (Granja) beach stretches used for analysis (ETRS89/TM06 coordinates).

\begin{tabular}{|c|c|c|c|c|c|c|c|c|c|}
\hline \multirow[b]{3}{*}{ Period } & \multicolumn{9}{|c|}{$\Delta$ Volume $\left(1000 \mathrm{~m}^{3}\right)$} \\
\hline & \multicolumn{3}{|c|}{ North } & \multicolumn{3}{|c|}{ Centre } & \multicolumn{3}{|c|}{ South } \\
\hline & total & gain & loss & total & gain & loss & total & gain & loss \\
\hline Mar.01 to Mar.02 & 29,7 & 68,6 & $-38,6$ & $-7,9$ & 2,6 & $-10,3$ & & & \\
\hline Mar.02 to Mar.03 & 77,4 & 127,8 & $-49,3$ & $-12,3$ & 0,1 & $-12,2$ & & & \\
\hline Mar.03 to Mar.04 & 32,9 & 58,3 & $-25,3$ & 5,4 & 5,7 & $-0,3$ & & & \\
\hline Mar.04 to Feb.05 & 47,9 & 66,6 & $-18,8$ & 8,9 & 9,3 & $-0,4$ & 12,7 & 24,1 & $-11,3$ \\
\hline Feb.05 to Mar.06 & 75,9 & 84,1 & $-7,7$ & 2 & 6 & -4 & -8 & 8,6 & $-16,6$ \\
\hline Mar.06 to Dec.07 & $-28,4$ & 29,5 & $-58,1$ & $-8,2$ & 1,5 & $-9,7$ & $-19,7$ & 7,8 & $-27,5$ \\
\hline Dec.07 to Mar.08 & 15 & 32,7 & $-17,7$ & $-0,8$ & 0,7 & $-1,5$ & $-4,6$ & 8,3 & $-12,5$ \\
\hline Mar.08 to Apr.09 & 135,3 & 140,2 & $-4,7$ & 29,7 & 29,8 & $-0,1$ & - & - & - \\
\hline Apr.09 to May 10 & 64,3 & 77,4 & -13 & 6,2 & 6,4 & $-0,1$ & 13,2 & 22,5 & $-9,2$ \\
\hline Average & 50,0 & 76,1 & $-25,9$ & 2,6 & 6,9 & $-4,3$ & $-1,3$ & 14,3 & $-15,4$ \\
\hline
\end{tabular}

Fig. 5 Changes $(\Delta)$ in volume between surveys, for the three sectors (North, Centre and South). The overall volume budget (total), volume of accretion (gain) and erosion (loss) are given. 

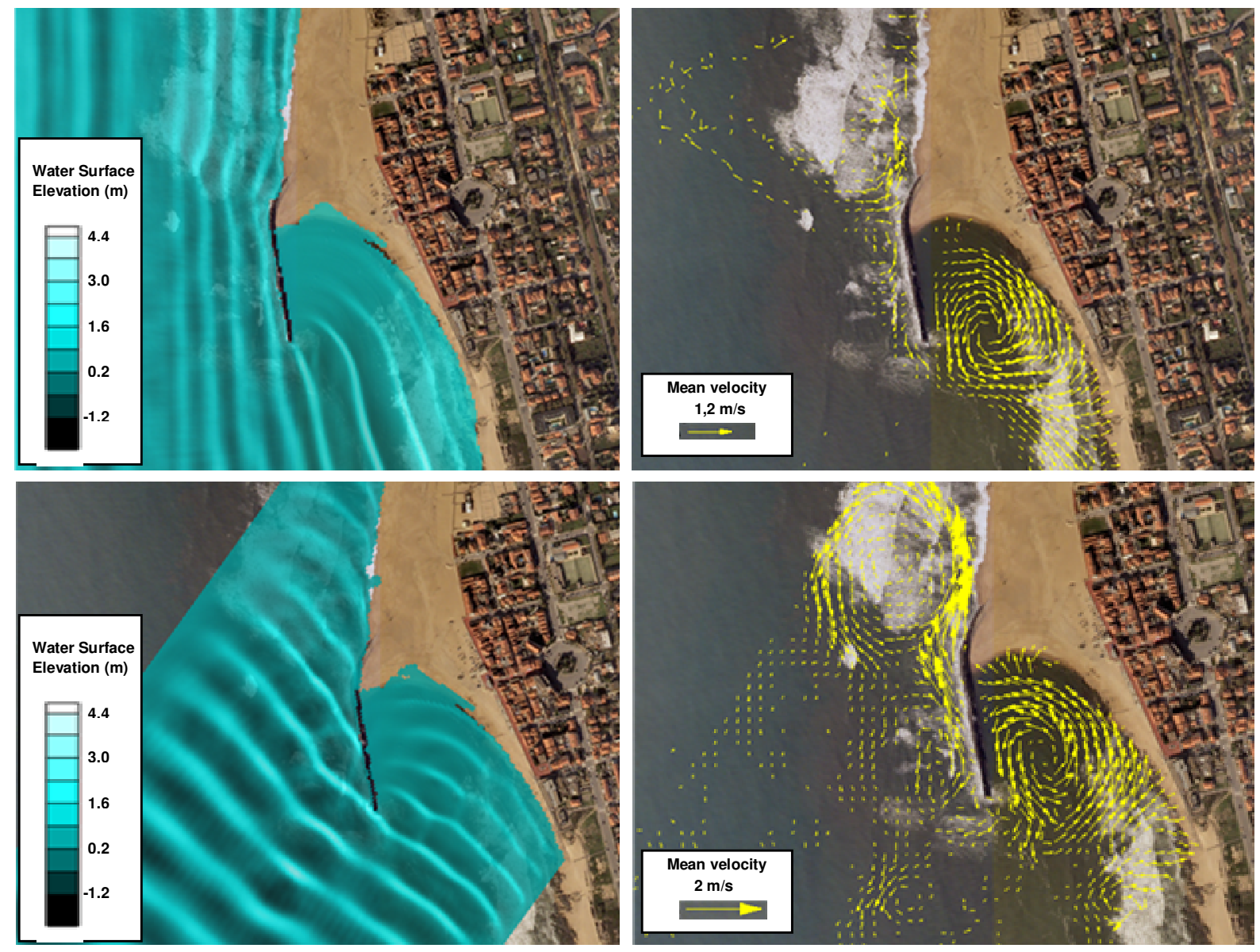

Fig. 6 Wave transformation in the Aguda breakwater vicinity for irregular waves coming from west (upper pictures) and for irregular waves coming from southwest (lower pictures).

For the most frequent local wave dynamics (waves from NW and W) the coastal defense structure reveals to be efficient protecting the fishery boats navigation. However, the inversion of the local sedimentary drift suggested by the obtained model results and the monitored sediment deficits verified at the South segment reveals that this structure presents maintenance costs (associated with beach nourishment at South and dredging inside the protected bay) that were not predicted before its construction. Its evaluation should be done in the future and alternatives to the present structure configuration should be evaluated in order to obtain a better performance. Design of such structures must consider the particular behavior characteristics of this coastal segment that is mainly formed of pocket beaches constituted by sands confined between the urban area and the rocky platform.

\section{Conclusions}

Applied survey methods allow the attainment of 3D images and DTM of a coastal segment during and after the construction of a coastal defense structure. DTM results were processed in order to derive annual sediment budgets for this coastal stretch.

The structure is inducing a sediment deficit at the South segment due to inversion of the prevailing North-South sedimentary drift in this coastal area and its main purpose (navigation) is being affected by deposition of sands inside the formed bay. 
Correct assessment for improvement of the actual situation needs a complete characterization of the sediments dynamics, mainly based on field surveys at this coastal stretch, since it presents singular characteristics concerning the high-energy wave climate and the movable sands deposits dynamics between the rocky platform and the urban front.

\section{References}

Baptista P., Bastos L., Bernardes C., Cunha T. and Dias J., 2008a. Monitoring Sandy Shores Morphologies by DGPS. A Practical Tool to Generate Digital Elevation Models. Journal of Coastal Research, 24, 1516-1528.

Baptista P., Bastos L., Cunha T., Bernardes C. and Dias J., 2008b. Aplicação de metodologias de monitorização GPS em litorais arenosos: Geração de modelos de elevação do terreno. Revista da Gestão Costeira Integrada 8, 9̃23. (in Portuguese).

Bastos L., Madeira S. and Gonçalves J., 2009. A Land Based MMS for Coastal Monitoring, oral presentation at the IAG2009 Assembly, Buenos Aires, Argentina, August-September 2009.

Gonçalves J.A., Bastos L., Perez B. and Magalhães, A., 2010. Monitoring of beaches and sand dunes using digital aerial photography with direct georeferencing. In: Wagner, W., Székely, B. (eds.): ISPRS TC VII Symposium - 100 Years ISPRS, Vienna, Austria, July 5-7, 2010, IAPRS, Vol. XXXVIII, Part 7B, pp. 228-232.

IGP, 2010. http://www.igeo.pt/produtos/geodesia/vg/renep/renep.asp (last assessed on April 2010)

INAG, 2010 http://www.inag.pt (last assessed on May 2010)

Jacobsen K., 2000. Program System BLUH user's manual. Institute of Photogrammetry and Engineering Surveys, University of Hanover, Hanover, 444pp.

Madeira S., 2007. Sistema Móvel Terrestre de Levantamento com Integração em SIG. PhD Thesis, Universidade do Porto (in Portuguese).

Nawogu G. and Demirbilek Z., 2001. BOUSS-2D: A Boussinesq Wave Model for Coastal Regions and Harbors. Report 1. Theoretical Background and User's Manual. US Army Corps of Engineers. Engineer Research and Development Center. USA.

Rieke-Zapp D.H. and Nearing M.A., 2005. Digital Close Range Photogrammetry for Measurement of Soil Erosion. The Photogrammetric Record, 20(109), 69-87.

Rosa-Santos P., Veloso-Gomes F., Taveira-Pinto F., Silva R., Pais-Barbosa J., 2009. Evolution of Coastal Works in Portugal and their Interference with Local Morphodynamics, Journal of Coastal Research, Special Issue 56, pp. 757-761.

\section{Acknowledgements}

The authors gratefully acknowledge to Parque Biológico de Gaia, SA., for the financial support to carry out the monitoring program 2008-2010. 